\title{
The Role of the Cerebellum in Multiple Sclerosis
}

Katrin Weier, Brenda Banwell, Antonio Cerasa, D. Louis Collins, Anne-Marie Dogonowski, Hans Lassman, Aldo

Quattrone, Mohammad A. Sahraian, Hartwig R. Siebner, and Till Sprenger

The Cerebellum June 2015, Volume 14, Issue 3, pp 364-374

doi: $10.1007 / \mathrm{s} 12311-014-0634-8$

http://link.springer.com/article/10.1007\%2Fs12311-014-0634-8 


\title{
CONSENSUS PAPER \\ "THE ROLE OF THE CEREBELLUM IN MULTIPLE SCLEROSIS"
}

Katrin Weier, MD; Brenda Banwell, MD; Antonio Cerasa, PhD; D. Louis Collins, PhD;

Anne-Marie Dogonowski, MD/PhD; Hans Lassmann, MD; Aldo Quattrone, MD;

Mohammad A. Sahraian, MD; Hartwig. R. Siebner, MD; Till Sprenger, MD.

\section{Affiliations:}

Katrin Weier, MD

McConnell Brain Imaging Center, Montreal Neurological Hospital and Institute, McGill University,

Montreal, Canada and Department of Neurology, University Hospital Basel, Basel Switzerland

Brenda Banwell, MD

Children's Hospital of Philadelphia, University of Pennsylvania, Philadelphia, US

\section{Antonio Cerasa, PhD}

IBFM, National Research Council, Catanzaro, Italy

\section{Louis Collins, PhD}

McConnell Brain Imaging Center, Montreal Neurological Hospital and Institute and Department

Biomedical Engineering, McGill University, Montreal, Canada

\section{Anne-Marie Dogonowski, MD / PhD}

Danish Research Center for Magnetic Resonance, Copenhagen University Hospital Hvidovre, Hvidovre, Denmark

\section{Hans Lassmann, MD}

Center for Brain Research, Medical University of Vienna, Austria

\author{
Aldo Quattrone, MD \\ Institute of Neurology, University "Magna Graecia”, Germaneto (CZ), Italy \\ Mohammad A. Sahraian, MD \\ MS Research Center, Neuroscience Institute, Tehran University of Medical Sciences, Tehran-Iran

\section{Hartwig. R. Siebner, MD} \\ Danish Research Center for Magnetic Resonance, Copenhagen University Hospital Hvidovre, Hvidovre, \\ Denmark; Department of Neurology, Copenhagen University Hospital Bispebjerg, Copenhagen, Denmark
}

\section{Till Sprenger, MD}

Department of Neurology, University Hospital Basel, Basel Switzerland

Medical Image Analysis Center (MIAC) AG, University Hospital Basel, Basel Switzerland 


\section{Corresponding author:}

Katrin Weier, MD

Department of Neurology, University Hospital Basel, Petersgraben 4, 4031 Basel,

Switzerland. Tel. +41-61-265-2525, Fax.: +41-61-265-4100. Email: katrin.weier@usb.ch.

Keywords (max. 6): Multiple Sclerosis, cerebellum, cognition, magnetic resonance imaging, demyelination.

Word count: 5488; References: 89; Figures: 3; Tables: 0. 


\section{Conflict of interest statement}

K.W. received funding from the Swiss National Science Foundation (PBSKP3_145838). Dr. Weier reports no conflict of interest.

B.B. serves as a consultant to Novartis, Sanofi-Aventis, and Biogen-Idec. She is a senior editor of Multiple Sclerosis and Related Disorders.

A.C. reports no conflict of interest.

D.L.C discloses consulting for NeuroRx. He is co-founder of True Positive Medical Devices Inc.

A.M.D. has received speaker's fee from Biogen Idec and Merck-Serono and congress fee to ECTRIMS 2010 covered by Merck-Serono, Denmark.

H.L. reports no conflict of interest

Institute of Neurology, University "Magna Graecia”, Germaneto (CZ), Italy

A.Q. reports no conflict of interest.

M.A.S. reports that he has received travel grants to different congresses and symposiums from Biogen-idec, Biologix, Novartis, Merck-serono and Cinnagen and also received research supports from Iranian MS Society, Cinnagen, Merck-Serono and Novartis Iran.

H.S. has received honoraria as speaker from Lundbeck A/S, Valby, Denmark, Biogen Idec, Denmark A/S, Genzyme, Denmark and MerckSerono, Denmark, honoraria as editor from Elsevier Publishers, Amsterdam, The Netherlands and Springer Publishing, Stuttgart, Germany, and travel support from MagVenture, Denmark.

T.S. has received no personal compensation for consultancy activities. His employer, the University Hospital Basel, received compensation for him serving on scientific advisory boards from Novartis, ATI, Allergan, Teva, Genzyme and Biogen Idec. He has received research support from Novartis Switzerland, EFIC and the Swiss MS Society. 


\section{Abstract}

In Multiple Sclerosis (MS), cerebellar signs and symptoms as well as cognitive dysfunction are frequent and contribute to clinical disability with only poor response to symptomatic treatment. The current consensus paper highlights the broad range of clinical signs and symptoms of MS patients, which relate to cerebellar dysfunction. There is considerable evidence of cerebellar involvement in MS based on clinical, histopathological, as well as structural and functional magnetic resonance imaging (MRI) studies. The review of the recent literature, however, also demonstrates a high variability of results. These discrepancies are, at least partially, caused by the use of different techniques and substantial heterogeneity among the patient cohorts in terms of disease duration, number of patients, progressive vs relapsing disease courses. Moreover, the majority of studies were cross-sectional providing little insight into the dynamics of cerebellar involvement in MS. Some links between the histopathological changes, the structural and functional abnormalities as captured by MRI, cerebellar dysfunction and the clinical consequences are starting to emerge and warrant further study. A consensus is formed that this line of research will benefit from advances in neuroimaging techniques that allow to trace cerebellar involvement at higher resolution. Using a prospective study design, multimodal high-resolution cerebellar imaging is highly promising, particularly in patients who present with radiologically or clinically isolated syndromes or newly diagnosed MS. 


\section{Introduction}

\section{K.Weier, MD and T. Sprenger, MD}

Multiple sclerosis (MS) is the most common chronic disease of the central nervous system (CNS) leading to permanent disability in young adults. Over the past decades the focus of MS research has been predominantly on telencephalic structures. Evidence from these studies changed the traditional perception of inflammation and demyelination as the only pathological mechanisms in MS and helped to understand that neurodegenerative processes are involved and may even be key for the development of disability (1-3). This applies not only to the white but also extensively the grey matter, which is present from the earliest stages of the disease and accrues with disease progression (4). One macroscopic hallmark of both, inflammation and neurodegeneration is brain atrophy (5), which has been increasingly recognized as a viable biomarker of MS severity and disease progression (6) and can be readily investigated in vivo using structural magnetic resonance imaging $(\mathrm{MRI})$.

The cerebellum is functionally and anatomically a fascinating, but complex structure. The cerebellum has the highest growth rate of all brain structures during the late fetal and early postnatal life, reaching its adult cell count only by the age of two years (7). The cortical grey matter is tightly folded (foliae) and includes thin layers of white matter, which branch to form the medullary core. The latter as well as its location in the posterior fossa with its dense vascular bed have technically hampered structural and functional MRI studies of the cerebellum in the past. Functionally the cerebellum is segregated in 
parallel cortico-nuclear sub-circuits that are integrated in various sensory-motor and cognitive-behavioural networks. Therefore, MS-related tissue damage of the cerebellum and the cerebro-cerebellar pathways affect a magnitude of brain functions and significantly contribute to the development of disability $(8,9)$. This applies particularly to patients with MS starting already in childhood or adolescence in whom the posterior fossa seems to be even more affected than in their adult-onset counterparts (10).

This consensus paper focuses on the involvement of the cerebellum in MS. Ten experts were invited to provide their perspective and discuss on the role of the cerebellum. Insights from recent histopathological, structural and functional MR imaging (fMRI) studies are highlighted. Further, the extent of clinical and cognitive disability and their relation to cerebellar changes in pediatric and adult-onset MS patients are discussed.

\section{Histopathological changes in the cerebellum in Multiple Sclerosis}

\section{H. Lassmann, $M D$}

MS is a chronic inflammatory disease, which leads to the formation of focal demyelinated plaques in the white and grey matter of the CNS. In addition to demyelination, neurodegeneration occurs to a variable degree, causing axonal loss within and outside of plaques in the white matter and neuronal loss in the grey matter (5). This may lead to profound tissue loss and atrophy in the entire brain. In most patients MS starts with an early phase of relapsing remitting disease, which after 10 to 15 years 
converts into a secondary progressive phase. Some patients lack a relapsing stage and the disease starts gradually with a slowly progressive deterioration (primary progressive MS) (11). The age of the patient is a major determining factor associated with the conversion from relapsing to progressive disease (12). In pathology, focal white matter lesions associated with profound inflammation, dominate the early relapsing phase. With disease duration the inflammatory response declines, new focal white matter lesions become rare, but cortical demyelination, diffuse damage of the normal appearing white matter and brain atrophy are dominant (13). Current concepts suggest that MS is initiated and driven by the inflammatory process, but that with disease progression additional factors, related to accumulated brain damage, microglia activation, mitochondrial damage and age related iron accumulation in the human brain may amplify tissue injury and neurodegeneration (14). These changes, as they have been extensively characterized in the forebrain and the spinal cord, affect the cerebellum in a similar way.

Focal white matter lesions in the cerebellum. Focal white matter lesions can occur at any location of the central nervous system. It is thus not surprising that focal white matter lesions are also present in the cerebellum, predominantly located in the cerebellar peduncles and the hilar regions of the dentate and olivary nuclei (15). The reason for this location of lesions in these areas is unresolved but may at least in part be related to the vicinity to the ventricular system. Within the global brain, the percentage of lesions in the cerebellar white matter is lower compared to that in the forebrain white matter (15). This, however, seems to be due to the smaller volume of the cerebellar compared to the forebrain white matter, since the average plaque count per gram wet weight of tissue is 
similar (15). As in forebrain lesions, active and inactive white matter lesions can occur side by side and the lesions are characterized by complete primary demyelination, variable axonal loss and a variable extent of remyelination. Whether the extent of axonal loss or remyelination differs between cerebellar and forebrain plaques is currently unknown due to the lack of respective quantitative studies.

Cortical pathology. Three different types of cortical lesions are present in the forebrain cortex, cortico/subcortical lesions, intracortical lesions and subpial lesions (16). While cortico/subcortical and intracortical lesions develop around inflamed veins and venules, subpial lesions are associated with inflammation in the meninges $(17,18)$. In the cerebellum two different cortical lesion types are seen (19) (Figure 1). Cortico/subcortical lesions are frequently seen as extensions of white matter lesions in the folia, affecting the adjacent cortical tissue. The other type, which is much more abundant in particular in patients with progressive MS, consist of band like lesions, which span the cerebellar cortex over long distances of adjacent folia and do not reach the subcortical white matter (19). Similar to subpial lesions in the forebrain, they may be related to inflammation in the meninges, but a direct proof of this association is difficult due to the lack of myelinated fibers in the outer molecular layer of the cerebellar cortex. As in cortical lesions in the forebrain active demyelination in the cerebellar cortex is associated with a variable degree of acute axonal injury and loss. No systematic neuropathological studies are currently available on global neurodegeneration, nerve cell loss and atrophy in the cerebellar cortex. Reduction of Purkinje cell density has been seen in areas of cortical demyelination in comparison to normal appearing cortex of MS patients, but there was no 
significant reduction of nerve cell density in normal appearing MS cerebellar cortex compared to that in controls (19).

Cortical demyelination in the cerebellum is extensive in patients with progressive MS. In average 30 to $40 \%$ of the cortex is affected and in some patients nearly complete demyelination of the entire cortex is seen (19). Despite this dramatic observation, it is currently not clear, whether cortical demyelination in the cerebellum matters clinically. There is only a moderate density of myelinated nerve fibers in the cerebellar cortex, which includes radial fibers in the granular layer and two thin bands of myelinated fibers above and below the Purkinje cell layer. Whether a loss of myelin sheaths from these fibers has functional and clinically meaningful consequences is unclear. In cortical lesions of the forebrain the only neurophysiological consequence of demyelination has so far been identified as an acceleration of spreading depression (20).

\section{Cerebellar signs and symptoms in MS - more than the Charcot triad}

\section{M.A. Sahraian, $M D$}

Many clinical manifestations of MS arise from pathologies involving the cerebellum and cerebellar pathways. The huge number of cerebellar connections with other parts of the CNS such as the brainstem, cortex and spinal cord as well as dense fiber projections in the cerebellar peduncles makes this part of the brain an eloquent area in MS. Cerebellar symptoms were for a long time considered to be a common feature of MS. In fact, the French neurologist Jean-Martin Charcot (1825-1893) described his defining triad of MS 
as tremor, nystagmus and scanning speech (21). The exact prevalence of cerebellar signs and symptoms in MS is not clear. Overall it seems that cerebellar signs and symptoms represent the predominant clinical manifestation in $11-33 \%$ of patients with MS $(22,23)$. Cerebellar involvement may cause a wide range of signs and symptoms including tremor, gait and truncal ataxia, incoordination of voluntary movements, slurred speech, hypotonia, different kinds of nystagmus, ocular dysmetria and an inability to perform rapid alternating movements properly (dysdiadochokinesia). Depending on the extent of involvement, an individual may have one or a combination of signs and symptoms. Moreover, patients who exhibit clinical signs of cerebellar damage early in the disease course tend to develop severe disability more quickly (24).

Patients with MS should be carefully examined to detect possible cerebellar involvement. The examination should include stance, gait, finger-to-nose, heel-to-shin tests as well as rapid alternating hand movements. Different kinds of nystagmus (e.g. upbeat nystagmus) and abnormal speech patterns may also indicate cerebellar involvement. Tremor is one of the most common cerebellar symptoms in MS and may involve the head, neck, vocal cords, trunk and limbs. Tremor in MS typically involves the upper limbs and may cause severe disability and seriously impairs many activities of daily living. Postural and intention tremors are the two most prevalent types in MS. In a survey of tremors in MS, Alusi et al. demonstrated that 58 out of 100 patients had tremor although it was not symptomatic in 20 patients. The tremor was minimal in $27 \%$, mild in $16 \%$, and moderate to severe in $15 \%$ of the patients (25).

Head titubation defined as nodding head tremor with a frequency of 3-4 Hz has been reported in $9 \%$ of MS patients usually due to midline cerebellar lesions. Titubation of the 
head can occur in isolation or in combination with a postural tremor of the arms $(25,26)$. Gait ataxia is usually due to anterior lobe lesions and the severity of ataxia correlates with the level of disability and dependency caused by MS (27).

Lesions located in cerebellar midline structures may lead to truncal ataxia and complete astasia. These patients cannot stand upright without support. Paroxysmal bouts of ataxia and dysarthria with a characteristic temporal profile (sudden, brief, stereotyped attacks) have been reported in MS and may favorably respond to carbamazepine (28). Such patients typically have a midbrain lesion, which involves the crossing fibers of the cerebello-thalamo-cortical pathway (29). Nystagmus and ocular dysmetria usually results from dysfunction of cerebello-vestibular connections or lesions involving the dorsal vermis and fastigial nuclei. Gaze-evoked nystagmus, upbeat nystagmus, rebound nystagmus, and opticokinetic nystagmus may all be seen with midline cerebellar lesions. Other ocular lesions seen include opsoclonus, skew deviation and ocular bobbing. It should be noted that cerebellar deficits in MS contribute significantly to disability, often with poor response to symptomatic therapies. Moreover, cerebellar manifestations tend to be more persistent, even when they occur early in the course of the disease (30). 


\section{The cerebellum and neurocognitive dysfunction in MS}

\section{A. Cerasa, PhD and A. Quattrone, MD}

In recent years, a large amount of studies demonstrated a functional parcellation of the cerebellum driven by the connectivity between the cerebellum and primary brain cortices, pre-cerebellar nuclei and the spinal cord (31). Patients with focal lesions confined to the "motor" part of the cerebellum suffer from a well-characterized cerebellar motor syndrome, including dysmetria, dysarthia and ataxia (32). Moreover, a number of neuropsychological functions have also been demonstrated to be altered in patients with cerebellar lesions mainly including attention, working memory, and verbal fluency (33, 34). Cerebellar lesions can result in a relatively well-defined "cerebellar cognitive affective syndrome" (33), a complex syndrome that includes executive dysfunctions and other cognitive deficits.

More recently, functional neuroimaging studies have further corroborated the critical role of the cerebellum in cognition providing a detailed topographic map of functional domains (35). In particular, lobule VI-VII and Crus I-II have been linked to language and working memory abilities. However, the role of the cerebellum in cognition depends on the existence of tight anatomical connections with a number of higher-level cortical regions. In particular, the prefrontal cortex, the superior temporal cortex and the lateral parietal cortex show diffuse projections to different cerebellar regions via the thalamus and the pons $(36,37)$.

The typical cognitive profile of patients with MS and cerebellar involvement still remains an important matter of debate. Generally, MS is a heterogeneous neurological disorder, 
both at the clinical and pathological level, characterized by diverse neurological symptoms including motor and cognitive dysfunctions. It is characteristic for MS that instead of a global cognitive decline, predominantly specific domains, in particular memory, language, attention and information processing speed, are affected (38). In the present literature, the relationship between cerebellar abnormalities and cognitive deficits is often elusive. However as said before, cerebellar signs and symptoms are a very common feature of patients with MS. The investigation of MS patients with cerebellar motor dysfunction (e.g. limb and/or gait ataxia, dysdiadochokinesia or tremor), offers a unique opportunity to disentangle the contribution of the cerebellum to cognitive dysfunction in MS patients. Only recently it has been demonstrated that MS patients with cerebellar motor signs suffer from more severe cognitive deficits with respect to patients without $(39,40)$. In fact, MS patients with cerebellar motor dysfunction showed specific impairment in executive functions (Symbol Digit Modality Test $=$ SDMT; Paced Auditory Serial Addition Test $=$ PASAT) and language performance (Controlled Oral Word Association Test $=$ COWAT). Given that these specific deficits parallel those described in patients affected by "cerebellar cognitive affective syndrome" it is intriguing to study the role of the cerebellum in MS. As previously reported for patients with focal cerebellar lesions, the specific cognitive deficits detected in MS patients (with cerebellar motor dysfunction) might be dependent upon neural damage within cortical-cerebellar loops (32-34). For instance, one study demonstrated that during a working memory fMRI task, MS patients with cerebellar motor dysfunction, relative to both MS patients without and controls, displayed significantly reduced functional connectivity between the left cerebellar Crus I and the right superior parietal lobule, a cortical area implicated in short- 
term buffering and storage of relevant information (41). Moreover, two volumetric studies described significant correlations between the impairment of executive functions and loss of grey matter volumes in the cerebellum (40) and in the dorsolateral prefrontal cortex as well as between language performance and atrophy of the superior temporal cortex (42). The hypothesis that an altered communication of the cerebellum with higherorder cortical areas contributes to the dysfunctional cognitive profile of MS patients is indirectly supported by a recent volumetric study investigating patients with nondemyelinating focal cerebellar lesions (43). The authors described specific deficits in executive functions and language performance in association with grey matter reductions of the frontal and temporal cortices. However, it remains to be established how cerebellar white matter lesions characterizing MS patients with cerebellar motor dysfunction induce the detected grey matter tissue loss in associated cortical areas. It has been shown in the forebrain that cortical MS lesions develop with some predilection in areas that are connected to deep grey matter and white matter lesions (44). One possible explanation for this observation is that anterograde and retrograde degeneration lead to microglia activation, which may precipitate new lesion formation in the course of further inflammatory activation (45). This intriguing hypothesis remains to be specifically tested in the cerebellum e.g. with tractographic MRI and histopathological methods. The evidence described in this review supports the view that cerebellar signs contribute to cognitive impairments of patients with MS, influencing specific domains: executive functions and language. New therapeutic strategies targeting cerebellar cognitive symptoms (attentional deficits or language impairment) are therefore necessary in such patients. Recently it has been demonstrated that intensive computer-assisted cognitive 
rehabilitation tailored to MS patients with impaired attention influences neural plasticity and improves cognitive abilities (46). Similarly, repetitive transcranial brain stimulation may also be considered as an alternative non-pharmacological intervention for these patients, since its capacity to modulate neural networks to facilitate improvements in behavioral functions has been demonstrated in stroke patients with language deficits (47).

\section{What has structural MR imaging taught us about the cerebellar involvement in MS}

K. Weier, MD and D.L. Collins, PhD

Conventional MRI is the most important diagnostic tool in MS and infratentorial lesions were recognized early on to add to the predictive value in diagnosing MS (48). MRI using standard T1-, T2-weighted and fluid-attenuated inversion recovery (FLAIR) sequences is widely applied in clinical practice to identify focal lesions. In the current MRI criteria, which are part of the McDonald criteria for the diagnosis of MS (49), the posterior fossa is recognized as one out of four characteristic regions. One or more lesions in at least two of these regions are required to meet the MS criteria for dissemination in space (50).

More than 20 years ago, Baumhefner et al. could show a correlation between cerebellar lesion area, when measured on 2D coronal T2 weighted MRI scans (acquired on 0.35T), and disability in fine-motor tasks in progressive MS patients (51). However image quality in those days was low and post-processing methods limited. Further, evidence of a 
cerebellar volume reduction as determined using MRI was found in relapsing-remitting (RR) MS patients with severe cerebellar dysfunction when compared to healthy controls (HC), however, there was no correlation between Expanded Disability Status Scale (EDSS) (52) and cerebellar volume (53).

Over the past three decades it has been shown that an early diagnosis and treatment, before major neuronal damage has taken place, is beneficial in terms of the longer-term outcome (54). This is why there is a need to focus on early changes in the disease course. Furthermore, there is evidence that apart from inflammatory processes, neurodegeneration plays a major role in the MS pathobiology and both processes result in atrophy, and irreversible atrophy in turn leads to an accrual of disability (55). With the advent of higher magnet field strengths, improved gradients, coils and MRI sequences as well as advances in data post-processing techniques, atrophy measures of supratentorial brain structures have become important measures of disease activity. However in case of the cerebellum, technical challenges concerning correct segmentation of the thin cerebellar gyri and sulci and extracting the cerebellar tissue from nearby structures had hampered studies on cerebellar abnormalities in humans in the past, which have been overcome only recently $(56,57)$ (Figure 2 ). To date, mainly cross-sectional MRI data exist and only a few studies specifically focus on the role of the cerebellum in MS. T2 hypointensities in the dentate nuclei have been found in MS patients, possibly reflecting pathological non-heme iron deposition, and were related to ambulatory impairment and disability (58). While T2 hypointensities of the dentate nuclei do not seem to be disease specific (also seen in normal aging (59)), equivalent bilateral T1 hyperintensities in the dentate nuclei have so far only been reported in MS patients (60). 
T1 hyperintensities of the dentate nuclei appear mainly to be associated with the secondary progressive disease subtype and with increased clinical disability, lesion load, and brain atrophy (60).

T1-weighted MRI can further be used to determine disease-related cerebellar atrophy and more specifically reduced cerebellar grey and white matter volume. Overall, studies show a clear reduction of the total cerebellar volume in patients with MS (ranging between $106-150 \mathrm{cc}$ ) when compared to $\mathrm{HC}$, and this reduction is even more prominent in patients with a progressive disease course (61-64). Calabrese and colleagues (63) focused mainly on cerebellar cortical volume and found reduced volumes as well as evidence of cortical lesions as determined using double inversion recovery (DIR) sequences in all the different MS phenotypes (CIS, RR, secondary (SPMS) and primary progressive MS (PPMS)). In another cohort studied by Anderson et al., grey matter volume was significantly reduced in SPMS compared to HC. A borderline reduction was observed in RRMS. Regarding cerebellar white matter volume, changes were only seen in the SPMS group (61). Mesaros and colleagues compared grey matter changes between HC, MS patients with a benign disease course (disease duration of $\geq 15$ years and EDSS $\leq 3$ ) and SPMS using voxel based morphometry (VBM) (65). Interestingly the analysis of relative grey matter loss between SPMS and benign MS patients showed significant clusters predominantly in the cerebellum. The authors suggested that this grey matter loss may be a major determinant of locomotor disability in MS. In patients with CIS, results of previous studies are more heterogeneous: in one study, a volume reduction relative to $\mathrm{HC}$ was seen for cerebellar grey matter (63). In another study by Anderson and colleagues, no significant volume differences relative to HC were seen (61). In a VBM study of Henry et 
al., CIS patients also did not significantly differ from HC in cerebellar grey matter volume (66). As mentioned before, correlation with EDSS was at best moderate (63) or non existing $(53,62,65)$, however, more robust correlations between cerebellar volumes and clinical dysfunction were found when outcomes were chosen that tested specifically for fine-motor skills, locomotion, or cognition $(40,61,66,67)$.

Taken together, there is a high variability regarding the results (and conclusions) of these structural MRI studies. This may be explained by the usage of different techniques [semiautomated versus automated segmentation, VBM versus region-of-interest (ROI) techniques, etc.], arbitrarily chosen anatomical boundaries towards the brainstem and heterogeneity in patient cohorts (disease duration, number of patients). It is also important to note that the white matter in the thin foliae cannot be easily separated from the cortical grey matter using most of the techniques applied in the available literature, nor were the cerebellar nuclei distinguished from the white matter core. These limitations have to be kept in mind, when interpreting results on cerebellar grey and white matter changes in MS patients.

\title{
Insights from advanced MRI studies of the cerebellum in MS
}

\author{
H. Siebner, MD, DMSci and A.-M. Dogonowski, MD, PhD
}

In recent years, diffusion weighted magnetic resonance imaging (DWI) has emerged as another important MRI modality. Applying a diffusion tensor (DT) model to the DWI data, one can derive well-established voxel-wise measures of regional water diffusion 
such as fractional anisotropy (FA), mean diffusivity (MD), or directional diffusivity. These DT measures can be used to detect MS-related microstructural changes in cerebellar white and grey matter, especially in the cerebellar peduncles, which contain the main white-matter pathways linking the cerebellum with the rest of the brain (68). Several recent DT MRI studies have examined the association between clinical disability and the degree of white-matter damage in the middle and superior cerebellar peduncles (68). Inter-individual variations of DT-based microstructural measures in the superior cerebellar peduncles were found to correlate with upper limb function and walking in progressive MS patients (68) and with balance impairment as measured by static posturography (69). RRMS patients with worse balance performance displayed stronger increases in regional MD and decreases in regional FA in the superior and middle cerebellar peduncles along with other pathways in the brain stem and cerebral white matter (69). Postural impairment also correlated with cerebellar grey matter reductions in the anterior lobules IV, V, VI and lobules VIII (69). In a large cohort of $172 \mathrm{MS}$ patients of various phenotypes, focal lesions were frequently present on T2-weighted images in the middle (65\% of patients) and superior cerebellar peduncles (43\% of patients) (70). Compared with volumetric measures of T2 lesions or cerebellar atrophy, DT MRI of the cerebellar peduncles had a superior discriminatory power to distinguish between impaired and unimpaired subgroups according to their cerebellar and brainstem functional system scores. Clinically impaired patients had significantly higher MD and radial diffusivity and lower FA values in the middle and superior cerebellar peduncles relative to clinically unimpaired patients (70). 
Another way to use DWI is to apply tractography approaches such as anatomical connectivity mapping (ACM) to quantify structural brain connectivity in MS. A recent DWI study reported an association between the ACM values in the inferior middle cerebellum (lobules IX) and patient's cognitive ability as reflected by the PASAT score (71).

MS-related alterations in functional connectivity of the cerebellum can be probed with blood oxygenation level-dependent (BOLD) fMRI while the patient is at rest or performs an experimental task. A link between impaired local functional integration in the cerebellum and lesion load of the cerebellar peduncles was recently demonstrated in a resting-state fMRI study which used a regional homogeneity measure of resting-state BOLD-signal fluctuations as index of local regional connectivity within the cerebellar cortex (72): The left lobules V and VI expressed reduced local functional connectivity in patients with MS relative to controls (Figure 3). In addition, patients with higher EDSSor ataxia-scores displayed a stronger reduction of local connectivity in the left Crus I and dentate nucleus compared to patients with lower EDSS- or ataxia scores (Figure 3). Impaired local functional connectivity in the cerebellar cortex might reflect a temporospatial disintegration of converging cortico-ponto-cerebellar and spino-cerebellar inputs induced by MS lesions in cerebellar white-matter tracts. In support of this interpretation, local connectivity in the cerebellum decreased with increasing lesion load of the left cerebellar peduncle (72).

Other task-related fMRI studies have shown that MS alters the functional connectivity between the cerebellum and cortical frontoparietal areas of the brain. An abnormal pattern of connectivity between premotor cortex and cerebellum was first reported by 
Saini et al. during a handwriting task (73). A recent fMRI study demonstrated functional connectivity changes between the right cerebellum and prefrontal areas during a Stroop interference task that depended on the clinical phenotype of MS (74). In that study, patients' response times in the incongruent Stroop condition inversely correlated with bilateral cerebellar activity and disease duration inversely correlated with right cerebellar activity. Changes in cerebello-cortical functional connectivity has been found in several other fMRI studies using motor (75) or cognitive tasks (76). For instance, Loitfelder et al. computed functional connectivity of the anterior cingulate cortex (ACC) based on rest periods of a block-design fMRI study (77). Better cognitive performance in the patients as reflected by the individual PASAT score was associated with increased functional connectivity between ACC and Crus I and left lobule VI of the cerebellum. Although the changes in functional connectivity of the cerebellum differ to some degree across studies, these studies show that the MS-induced structural damage in cortico-cerebellar networks triggers functional changes in the cerebellum. Whether these changes reflect a primary dysfunction, compensation, or maladaptive changes remains to be determined. To tackle this question, longitudinal multimodal MRI studies on newly diagnosed MS patients are warranted in which structural and functional changes in cortico-cerebellar connectivity are prospectively assessed and related to lesion accumulation, atrophy development and measures of motor and cognitive disability. 


\title{
The role of the cerebellum in pediatric-onset MS
}

\author{
K. Weier, MD and B. Banwell, MD
}

Over the past two decades pediatric-onset MS has been increasingly recognized. About 2$5 \%$ of all MS patients experience disease onset before the age of $18(78,79)$. The femalemale ratio is equal before puberty and by adolescence the strong female preponderance resembles that of adult-onset disease (80). The clinical features of MS in children differ slightly from those of adults, particularly in the youngest patients, although the relapsingremitting disease course and subsequent relapse features are typical of relapsing-remitting disease in adult-onset patients $(81,82)$. More than half of the pediatric-onset MS patients experience a polyfocal presentation, $30-50 \%$ initially present with deficits referable to a single site in the CNS. While optic neuritis and sensory deficits are one of the most common initial presentations, cerebellar dysfunction including ataxia and oculomotor disturbances are notable in 5-27\% of pediatric-onset MS patients, with ataxia occurring in approximately $50 \%$ of the children who manifest with their first MS attack prior to age 10 years $(80,83,84)$. The presence of cerebellar symptoms does not predict relapse severity or clinical recovery from relapse (85).

The cerebellum is also an important brain region for cognitive-behavioral processing (86). Studies of pediatric MS cohorts have demonstrated that 30-50\% have cognitive impairment detected within the first five years of MS onset $(87,88)$. The contribution of cerebellar MS pathology to cognitive impairment has yet to be fully appreciated. Of interest, however, are MRI studies demonstrating that the posterior fossa is more likely to be affected in pediatric-onset patients when compared to adult-onset MS, with pediatric- 
onset MS patients showing a higher lesion burden in the cerebellar peduncles and cerebellar white matter as compared to disease-duration matched adult-onset MS patients $(10,89)$. The impact of the latter on changes of the cerebellar grey matter volume and functional consequences are still lacking. Resting state fMRI permits the evaluation of functional connectivity within and among functional brain networks at rest. Rocca and colleagues found decreased functional connectivity in the cerebellar lobule VI (as part of the sensorimotor network) and the cerebellar vermis (as part of the secondary visual network) in pediatric MS patients when compared to age- and sex-matched HC (90). The functional significance of such regional decreases in intra-network connectivity and its correlation with cognitive performance are not yet known. Conceptually, white matter lesions may disrupt both established and developing neural networks. Replication of the fMRI data will be required, as inter-individual variability, the disease duration, and compensatory up-regulation of functional connections in the CNS are all likely to impact the results in the context of MS.

In summary, clinical and MRI evidence indicates significant cerebellar involvement in pediatric-onset MS. More knowledge is required to more fully appreciate the impact of lesional burden on cerebellar integrity, maturation and connectivity. Given the important role of the cerebellum in cognitive processing, the causal links between cerebellar pathology and cognitive performance in pediatric MS patients should be explored in more detail. 


\section{Conclusion and future perspectives}

K. Weier, MD and T. Sprenger, $M D$

Ten expert opinions from MS researchers with different research focus were collected for this consensus paper. All contributors fully agreed that the cerebellum is a major target for MS and cerebellar involvement contributes to a considerable degree to disease-related impairment in MS, especially in progressive forms of the disease. There was general consensus that cerebellar signs and symptoms had been early recognized as frequent and disabling in MS (Charcot's defining triad of MS), yet the "little brain" did not play a major role in MS research for a long time and research focused mainly on supratentorial and spinal structures. Interest on the cerebellum in MS has increased over the past decade and the number of studies addressing the impact of the disease on the cerebellar structure and function is steadily increasing. Widespread demyelination of the cerebellar cortex has been found histopathologically in MS patients and volume loss as well as evidence for microstructural changes in comparison to $\mathrm{HC}$ has been confirmed in cross-sectional MRI studies. The question remains for future work to determine to what extent this bears functional consequences over time and if the pathological changes directly explain the frequent clinical signs and symptoms thought to be of cerebellar origin. The correlation reported between clinical and MRI measures of cerebellar pathology is moderate to weak and more consistently found in progressive disease and after longer disease duration. Cognitive deficits related to the cerebellum occur in parallel to cerebellar motor dysfunction. 
According to the authors one explanation for the rather weak link between functional deficits and underlying pathology may relate to the complex anatomical architecture of the cerebellum. The tightly folded cortex and its difficult demarcation to the white matter challenges the segmentation techniques, which have been mainly designed for and validated on supratentorial structures and for cross-sectional studies. Limited grey-white matter classification accuracy may also result in questionable classification of white versus grey matter lesions. Furthermore, intra-cortical demyelinated lesions so far escape detection by MRI due to the extremely low myelin content in the cerebellar cortex. Functional imaging studies have demonstrated cerebellar activation changes in MS patients compared to HC. However, whether such changes reflect a primary dysfunction due to corresponding structural changes, compensation mechanisms, or maladaptive neuroplasticity remains elusive as is a topic for future work. The functional importance of the cerebellum as a strategic node in various networks (motor, coordination, cognitivebehavioural loops) with its multiple connections to different cortical areas of the forebrain, the thalamus and the spinal cord makes it difficult or even impossible to identify distinct tasks, which solely reflect cerebellar function.

Given the constant technical advances, it is likely that some of the limitations inherent to currently available neuroimaging techniques will be overcome in the next years. The authors are convinced that the increasing use of MR magnets with higher field strengths will yield better image quality and higher anatomical resolution, which will improve the accuracy of segmentation techniques. Advanced imaging techniques such as diffusion spectrum imaging, which allows more accurate mapping of axonal trajectories (91), bear the possibility to detect subtle structural alterations of cerebellar pathways in MS in the 
future (92). Furthermore, there was agreement that the combination of structural and functional imaging in correlation to clinical tests over a certain period of time is necessary to fill the gap and better understand the functional consequences of structural damage in the cerebellum of MS patients and hence improve the predictive value of the latter in the long run. Identification of MS imaging phenotypes related to predominant signs of cerebellar dysfunction potentially pointing to a worse prognosis would impact early therapeutic strategies.

For future studies, the authors suggest a systematic, multimodal approach to study the cerebellum in relation to its functionally-related brain structures in patients with radiologically isolated or clinically isolated syndromes or newly diagnosed MS and study changes longitudinally. 


\section{References}

1. Reynolds R, Roncaroli F, Nicholas R, Radotra B, Gveric D, Howell O. The neuropathological basis of clinical progression in multiple sclerosis. Acta Neuropathol. 2011 Aug;122(2):155-70. PubMed PMID: 21626034. Epub 2011/06/01. eng.

2. Miller DH, Barkhof F, Frank JA, Parker GJ, Thompson AJ. Measurement of atrophy in multiple sclerosis: pathological basis, methodological aspects and clinical relevance. Brain. 2002 Aug;125(Pt 8):1676-95. PubMed PMID: 12135961.

3. Fisher E, Rudick RA, Simon JH, Cutter G, Baier M, Lee JC, et al. Eight-year follow-up study of brain atrophy in patients with MS. Neurology. 2002 Nov 12;59(9):1412-20. PubMed PMID: 12427893. Epub 2002/11/13. eng.

4. Geurts JJ, Calabrese M, Fisher E, Rudick RA. Measurement and clinical effect of grey matter pathology in multiple sclerosis. Lancet Neurol. 2012 Dec;11(12):1082-92. PubMed PMID: 23153407.

5. Lassmann H, Bruck W, Lucchinetti CF. The immunopathology of multiple sclerosis: an overview. Brain Pathol. 2007 Apr;17(2):210-8. PubMed PMID: 17388952. 6. De Stefano N, Airas L, Grigoriadis N, Mattle HP, O'Riordan J, Oreja-Guevara C, et al. Clinical relevance of brain volume measures in multiple sclerosis. CNS drugs. 2014 Feb;28(2):147-56. PubMed PMID: 24446248.

7. Dobbing J, Sands J. Quantitative growth and development of human brain. Archives of disease in childhood. 1973 Oct;48(10):757-67. PubMed PMID: 4796010. Pubmed Central PMCID: 1648530. 
8. Eriksson M, Andersen O, Runmarker B. Long-term follow up of patients with clinically isolated syndromes, relapsing-remitting and secondary progressive multiple sclerosis. Mult Scler. 2003 Jun;9(3):260-74. PubMed PMID: 12814173.

9. Miller DH, Hornabrook RW, Purdie G. The natural history of multiple sclerosis: a regional study with some longitudinal data. J Neurol Neurosurg Psychiatry. 1992 May;55(5):341-6. PubMed PMID: 1602305.

10. Ghassemi R, Narayanan S, Banwell B, Sled JG, Shroff M, Arnold DL, et al. Quantitative determination of regional lesion volume and distribution in children and adults with relapsing-remitting multiple sclerosis. PloS one. 2014;9(2):e85741. PubMed PMID: 24586244. Pubmed Central PMCID: 3935826.

11. Lublin FD, Reingold SC. Defining the clinical course of multiple sclerosis: results of an international survey. National Multiple Sclerosis Society (USA) Advisory Committee on Clinical Trials of New Agents in Multiple Sclerosis. Neurology. 1996 Apr;46(4):907-11. PubMed PMID: 8780061.

12. Scalfari A, Neuhaus A, Daumer M, Ebers GC, Muraro PA. Age and disability accumulation in multiple sclerosis. Neurology. 2011 Sep 27;77(13):1246-52. PubMed PMID: 21917763. Pubmed Central PMCID: 3179646.

13. Kutzelnigg A, Lucchinetti CF, Stadelmann C, Bruck W, Rauschka H, Bergmann M, et al. Cortical demyelination and diffuse white matter injury in multiple sclerosis. Brain. 2005 Nov;128(Pt 11):2705-12. PubMed PMID: 16230320.

14. Lassmann H, van Horssen J, Mahad D. Progressive multiple sclerosis: pathology and pathogenesis. Nature reviews Neurology. 2012 Nov 5;8(11):647-56. PubMed PMID: 23007702. 
15. Lumsden CE. The neuropathology of multiple sclerosis. . In: Vinken PI, Bruyn GW, editors. Handbook of clinical neurology. 9. New York: Elsevier; 1970. p. 217-309. 16. Peterson JW, Bo L, Mork S, Chang A, Trapp BD. Transected neurites, apoptotic neurons, and reduced inflammation in cortical multiple sclerosis lesions. Ann Neurol. 2001 Sep;50(3):389-400. PubMed PMID: 11558796.

17. Choi SR, Howell OW, Carassiti D, Magliozzi R, Gveric D, Muraro PA, et al. Meningeal inflammation plays a role in the pathology of primary progressive multiple sclerosis. Brain. 2012 Oct;135(Pt 10):2925-37. PubMed PMID: 22907116.

18. Howell OW, Reeves CA, Nicholas R, Carassiti D, Radotra B, Gentleman SM, et al. Meningeal inflammation is widespread and linked to cortical pathology in multiple sclerosis. Brain. 2011 Sep;134(Pt 9):2755-71. PubMed PMID: 21840891.

19. Kutzelnigg A, Faber-Rod JC, Bauer J, Lucchinetti CF, Sorensen PS, Laursen H, et al. Widespread demyelination in the cerebellar cortex in multiple sclerosis. Brain Pathol. 2007 Jan;17(1):38-44. PubMed PMID: 17493036.

20. Merkler D, Klinker F, Jurgens T, Glaser R, Paulus W, Brinkmann BG, et al. Propagation of spreading depression inversely correlates with cortical myelin content. Ann Neurol. 2009 Sep;66(3):355-65. PubMed PMID: 19798729.

21. Poser CM, Brinar VV. Diagnostic criteria for multiple sclerosis. Clin Neurol Neurosurg. 2001 Apr;103(1):1-11. PubMed PMID: 11311469.

22. Rot U, Ledinek AH, Jazbec SS. Clinical, magnetic resonance imaging, cerebrospinal fluid and electrophysiological characteristics of the earliest multiple sclerosis. Clin Neurol Neurosurg. 2008 Mar;110(3):233-8. PubMed PMID: 18093725. 
23. Weinshenker BG, Issa M, Baskerville J. Long-term and short-term outcome of multiple sclerosis: a 3-year follow-up study. Arch Neurol. 1996 Apr;53(4):353-8. PubMed PMID: 8929158.

24. Amato MP, Ponziani G. A prospective study on the prognosis of multiple sclerosis. Neurol Sci. 2000;21(4 Suppl 2):S831-8. PubMed PMID: 11205358.

25. Alusi SH, Glickman S, Aziz TZ, Bain PG. Tremor in multiple sclerosis. J Neurol Neurosurg Psychiatry. 1999 Feb;66(2):131-4. PubMed PMID: 10071088. Pubmed Central PMCID: 1736223.

26. Proudlock FA, Gottlob I, Constantinescu CS. Oscillopsia without nystagmus caused by head titubation in a patient with multiple sclerosis. Journal of neuroophthalmology : the official journal of the North American Neuro-Ophthalmology Society. 2002 Jun;22(2):88-91. PubMed PMID: 12131465.

27. Weinshenker BG, Rice GP, Noseworthy JH, Carriere W, Baskerville J, Ebers GC. The natural history of multiple sclerosis: a geographically based study. 3. Multivariate analysis of predictive factors and models of outcome. Brain. 1991 Apr;114 ( Pt 2):104556. PubMed PMID: 2043940.

28. Twomey JA, Espir ML. Paroxysmal symptoms as the first manifestations of multiple sclerosis. J Neurol Neurosurg Psychiatry. 1980 Apr;43(4):296-304. PubMed PMID: 7373330. Pubmed Central PMCID: 490532.

29. Iorio R, Capone F, Plantone D, Batocchi AP. Paroxysmal ataxia and dysarthria in multiple sclerosis. Journal of clinical neuroscience : official journal of the Neurosurgical Society of Australasia. 2014 Jan;21(1):174-5. PubMed PMID: 23969003. 
30. Waxman SG. Cerebellar dysfunction in multiple sclerosis: evidence for an acquired channelopathy. Progress in brain research. 2005;148:353-65. PubMed PMID: 15661203.

31. Grimaldi G, Manto M. Topography of cerebellar deficits in humans. Cerebellum. 2012 Jun;11(2):336-51. PubMed PMID: 21240580.

32. Manto M, Bower JM, Conforto AB, Delgado-Garcia JM, da Guarda SN, Gerwig M, et al. Consensus paper: roles of the cerebellum in motor control--the diversity of ideas on cerebellar involvement in movement. Cerebellum. 2012 Jun;11(2):457-87. PubMed PMID: 22161499.

33. Schmahmann JD, Sherman JC. The cerebellar cognitive affective syndrome. Brain. 1998 Apr;121 ( Pt 4):561-79. PubMed PMID: 9577385.

34. Tedesco AM, Chiricozzi FR, Clausi S, Lupo M, Molinari M, Leggio MG. The cerebellar cognitive profile. Brain. 2011 Dec;134(Pt 12):3672-86. PubMed PMID: 22036960.

35. Stoodley CJ, Schmahmann JD. Evidence for topographic organization in the cerebellum of motor control versus cognitive and affective processing. Cortex. 2010 JulAug;46(7):831-44. PubMed PMID: 20152963.

36. Habas C, Kamdar N, Nguyen D, Prater K, Beckmann CF, Menon V, et al. Distinct cerebellar contributions to intrinsic connectivity networks. The Journal of neuroscience : the official journal of the Society for Neuroscience. $2009 \mathrm{Jul}$ 1;29(26):8586-94. PubMed PMID: 19571149. Pubmed Central PMCID: 2742620. 
37. Middleton FA, Strick PL. Basal ganglia and cerebellar loops: motor and cognitive circuits. Brain research Brain research reviews. 2000 Mar;31(2-3):236-50. PubMed PMID: 10719151.

38. Bobholz JA, Rao SM. Cognitive dysfunction in multiple sclerosis: a review of recent developments. Current opinion in neurology. 2003 Jun;16(3):283-8. PubMed PMID: 12858063.

39. Valentino P, Cerasa A, Chiriaco C, Nistico R, Pirritano D, Gioia M, et al. Cognitive deficits in multiple sclerosis patients with cerebellar symptoms. Mult Scler. 2009 Jul;15(7):854-9. PubMed PMID: 19542264.

40. Weier K, Penner IK, Magon S, Amann M, Naegelin Y, Andelova M, et al. Cerebellar abnormalities contribute to disability including cognitive impairment in multiple sclerosis. PloS one. 2014;9(1):e86916. PubMed PMID: 24466290. Pubmed Central PMCID: 3899307.

41. Cerasa A, Passamonti L, Valentino P, Nistico R, Pirritano D, Gioia MC, et al. Cerebellar-parietal dysfunctions in multiple sclerosis patients with cerebellar signs. Experimental neurology. 2012 Oct;237(2):418-26. PubMed PMID: 22892245.

42. Cerasa A, Valentino P, Chiriaco C, Pirritano D, Nistico R, Gioia CM, et al. MR imaging and cognitive correlates of relapsing-remitting multiple sclerosis patients with cerebellar symptoms. J Neurol. 2013 May;260(5):1358-66. PubMed PMID: 23271221. 43. Clausi S, Bozzali M, Leggio MG, Di Paola M, Hagberg GE, Caltagirone C, et al. Quantification of gray matter changes in the cerebral cortex after isolated cerebellar damage: a voxel-based morphometry study. Neuroscience. 2009 Sep 1;162(3):827-35. PubMed PMID: 19409211. 
44. Kolasinski J, Stagg CJ, Chance SA, Deluca GC, Esiri MM, Chang EH, et al. A combined post-mortem magnetic resonance imaging and quantitative histological study of multiple sclerosis pathology. Brain. 2012 Oct;135(Pt 10):2938-51. PubMed PMID: 23065787. Pubmed Central PMCID: 3470716.

45. Lassmann H. Cortical lesions in multiple sclerosis: inflammation versus neurodegeneration. Brain. 2012 Oct;135(Pt 10):2904-5. PubMed PMID: 23065786. 46. Cerasa A, Gioia MC, Valentino P, Nistico R, Chiriaco C, Pirritano D, et al. Computer-assisted cognitive rehabilitation of attention deficits for multiple sclerosis: a randomized trial with fMRI correlates. Neurorehabilitation and neural repair. 2013 May;27(4):284-95. PubMed PMID: 23192417.

47. Barwood CH, Murdoch BE, Whelan BM, Lloyd D, Riek S, JD OS, et al. Improved language performance subsequent to low-frequency rTMS in patients with chronic non-fluent aphasia post-stroke. European journal of neurology : the official journal of the European Federation of Neurological Societies. 2011 Jul;18(7):935-43. PubMed PMID: 21138505.

48. Barkhof F, Filippi M, Miller DH, Scheltens P, Campi A, Polman CH, et al. Comparison of MRI criteria at first presentation to predict conversion to clinically definite multiple sclerosis. Brain. 1997 Nov;120 ( Pt 11):2059-69. PubMed PMID: 9397021.

49. Polman CH, Reingold SC, Banwell B, Clanet M, Cohen JA, Filippi M, et al. Diagnostic criteria for multiple sclerosis: 2010 revisions to the McDonald criteria. Ann Neurol. 2011 Feb;69(2):292-302. PubMed PMID: 21387374. Pubmed Central PMCID: 3084507. 
50. Montalban X, Tintore M, Swanton J, Barkhof F, Fazekas F, Filippi M, et al. MRI criteria for MS in patients with clinically isolated syndromes. Neurology. 2010 Feb 2;74(5):427-34. PubMed PMID: 20054006.

51. Baumhefner RW, Tourtellotte WW, Syndulko K, Waluch V, Ellison GW, Meyers LW, et al. Quantitative multiple sclerosis plaque assessment with magnetic resonance imaging. Its correlation with clinical parameters, evoked potentials, and intra-blood-brain barrier IgG synthesis. Arch Neurol. 1990 Jan;47(1):19-26. PubMed PMID: 2294889.

52. Kurtzke JF. Rating neurologic impairment in multiple sclerosis: an expanded disability status scale (EDSS). Neurology. 1983 Nov;33(11):1444-52. PubMed PMID: 6685237.

53. Davie CA, Barker GJ, Webb S, Tofts PS, Thompson AJ, Harding AE, et al. Persistent functional deficit in multiple sclerosis and autosomal dominant cerebellar ataxia is associated with axon loss. Brain. 1995 Dec;118 ( Pt 6):1583-92. PubMed PMID: 8595487.

54. Freedman MS, Comi G, De Stefano N, Barkhof F, Polman CH, Uitdehaag BMJ, et al. Moving toward earlier treatment of multiple sclerosis: Findings from a decade of clinical trials and implications for clinical practice. Multiple Sclerosis and Related Disorders. 2014;3(2):147-55.

55. Bermel RA, Bakshi R. The measurement and clinical relevance of brain atrophy in multiple sclerosis. Lancet Neurol. 2006 Feb;5(2):158-70. PubMed PMID: 16426992. 56. Weier K, Fonov V, Lavoie K, Doyon J, Collins DL. Rapid automatic segmentation of the human cerebellum and its lobules (RASCAL)--implementation and application of the patch-based label-fusion technique with a template library to segment 
the human cerebellum. Hum Brain Mapp. 2014 Oct;35(10):5026-39. PubMed PMID: 24777876.

57. Park MT, Pipitone J, Baer LH, Winterburn JL, Shah Y, Chavez S, et al. Derivation of high-resolution MRI atlases of the human cerebellum at 3T and segmentation using multiple automatically generated templates. Neuroimage. $2014 \mathrm{Jul}$ 15;95:217-31. PubMed PMID: 24657354.

58. Tjoa CW, Benedict RH, Weinstock-Guttman B, Fabiano AJ, Bakshi R. MRI T2 hypointensity of the dentate nucleus is related to ambulatory impairment in multiple sclerosis. J Neurol Sci. 2005 Jul 15;234(1-2):17-24. PubMed PMID: 15993137.

59. Maschke M, Weber J, Dimitrova A, Bonnet U, Bohrenkamper J, Sturm S, et al. Age-related changes of the dentate nuclei in normal adults as revealed by 3D fast low angle shot (FLASH) echo sequence magnetic resonance imaging. J Neurol. 2004 Jun;251(6):740-6. PubMed PMID: 15311352.

60. Roccatagliata L, Vuolo L, Bonzano L, Pichiecchio A, Mancardi GL. Multiple sclerosis: hyperintense dentate nucleus on unenhanced T1-weighted MR images is associated with the secondary progressive subtype. Radiology. 2009 May;251(2):503-10. PubMed PMID: 19401576.

61. Anderson VM, Fisniku LK, Altmann DR, Thompson AJ, Miller DH. MRI measures show significant cerebellar gray matter volume loss in multiple sclerosis and are associated with cerebellar dysfunction. Mult Scler. 2009 Jul;15(7):811-7. PubMed PMID: 19465449. 
62. Weier K, Beck A, Magon S, Amann M, Naegelin Y, Penner IK, et al. Evaluation of a new approach for semi-automatic segmentation of the cerebellum in patients with multiple sclerosis. J Neurol. 2012 Dec;259(12):2673-80. PubMed PMID: 22711160. 63. Calabrese M, Mattisi I, Rinaldi F, Favaretto A, Atzori M, Bernardi V, et al. Magnetic resonance evidence of cerebellar cortical pathology in multiple sclerosis. J Neurol Neurosurg Psychiatry. 2010 Apr;81(4):401-4. PubMed PMID: 19965849. 64. Ramasamy DP, Benedict RH, Cox JL, Fritz D, Abdelrahman N, Hussein S, et al. Extent of cerebellum, subcortical and cortical atrophy in patients with MS: a case-control study. J Neurol Sci. 2009 Jul 15;282(1-2):47-54. PubMed PMID: 19201003.

65. Mesaros S, Rovaris M, Pagani E, Pulizzi A, Caputo D, Ghezzi A, et al. A magnetic resonance imaging voxel-based morphometry study of regional gray matter atrophy in patients with benign multiple sclerosis. Arch Neurol. 2008 Sep;65(9):1223-30. PubMed PMID: 18779427.

66. Henry RG, Shieh M, Okuda DT, Evangelista A, Gorno-Tempini ML, Pelletier D. Regional grey matter atrophy in clinically isolated syndromes at presentation. J Neurol Neurosurg Psychiatry. 2008 Nov;79(11):1236-44. PubMed PMID: 18469033.

67. Damasceno A, Damasceno BP, Cendes F. The clinical impact of cerebellar grey matter pathology in multiple sclerosis. PloS one. 2014;9(5):e96193. PubMed PMID: 24789257. Pubmed Central PMCID: 4008536.

68. Anderson VM, Wheeler-Kingshott CA, Abdel-Aziz K, Miller DH, Toosy A, Thompson AJ, et al. A comprehensive assessment of cerebellar damage in multiple sclerosis using diffusion tractography and volumetric analysis. Mult Scler. 2011 Sep;17(9):1079-87. PubMed PMID: 21511688. Pubmed Central PMCID: 3281565. 
69. Prosperini L, Sbardella E, Raz E, Cercignani M, Tona F, Bozzali M, et al. Multiple sclerosis: white and gray matter damage associated with balance deficit detected at static posturography. Radiology. 2013 Jul;268(1):181-9. PubMed PMID: 23533287. 70. Preziosa P, Rocca MA, Mesaros S, Pagani E, Drulovic J, Stosic-Opincal T, et al. Relationship between damage to the cerebellar peduncles and clinical disability in multiple sclerosis. Radiology. 2014 Jun;271(3):822-30. PubMed PMID: 24555637.

71. Bozzali M, Spano B, Parker GJ, Giulietti G, Castelli M, Basile B, et al. Anatomical brain connectivity can assess cognitive dysfunction in multiple sclerosis. Mult Scler. 2013 Aug;19(9):1161-8. PubMed PMID: 23325589.

72. Dogonowski AM, Andersen KW, Madsen KH, Sorensen PS, Paulson OB, Blinkenberg M, et al. Multiple sclerosis impairs regional functional connectivity in the cerebellum. NeuroImage Clinical. 2013;4:130-8. PubMed PMID: 24371795. Pubmed Central PMCID: 3871286.

73. Saini S, DeStefano N, Smith S, Guidi L, Amato MP, Federico A, et al. Altered cerebellar functional connectivity mediates potential adaptive plasticity in patients with multiple sclerosis. J Neurol Neurosurg Psychiatry. 2004 Jun;75(6):840-6. PubMed PMID: 15145996. Pubmed Central PMCID: 1739042.

74. Rocca MA, Bonnet MC, Meani A, Valsasina P, Colombo B, Comi G, et al. Differential cerebellar functional interactions during an interference task across multiple sclerosis phenotypes. Radiology. 2012 Dec;265(3):864-73. PubMed PMID: 22966067. 75. Rocca MA, Absinta M, Valsasina P, Ciccarelli O, Marino S, Rovira A, et al. Abnormal connectivity of the sensorimotor network in patients with MS: a multicenter fMRI study. Hum Brain Mapp. 2009 Aug;30(8):2412-25. PubMed PMID: 19034902. 
76. Rocca MA, Pagani E, Absinta M, Valsasina P, Falini A, Scotti G, et al. Altered functional and structural connectivities in patients with MS: a 3-T study. Neurology. 2007 Dec 4;69(23):2136-45. PubMed PMID: 18056577.

77. Loitfelder M, Filippi M, Rocca M, Valsasina P, Ropele S, Jehna M, et al. Abnormalities of resting state functional connectivity are related to sustained attention deficits in MS. PloS one. 2012;7(8):e42862. PubMed PMID: 22912754. Pubmed Central PMCID: 3422320.

78. Renoux C, Vukusic S, Mikaeloff Y, Edan G, Clanet M, Dubois B, et al. Natural history of multiple sclerosis with childhood onset. N Engl J Med. 2007 Jun 21;356(25):2603-13. PubMed PMID: 17582070.

79. Verhey LH, Shroff M, Banwell B. Pediatric multiple sclerosis: pathobiological, clinical, and magnetic resonance imaging features. Neuroimaging clinics of North America. 2013 May;23(2):227-43. PubMed PMID: 23608687.

80. Banwell B, Ghezzi A, Bar-Or A, Mikaeloff Y, Tardieu M. Multiple sclerosis in children: clinical diagnosis, therapeutic strategies, and future directions. Lancet Neurol. 2007 Oct;6(10):887-902. PubMed PMID: 17884679.

81. Chitnis T. Paediatric MS is the same disease as adult MS: no. Mult Scler. 2013 Sep;19(10):1255-6. PubMed PMID: 23996596.

82. Trojano M, Paolicelli D, Bellacosa A, Fuiani A, Cataldi S, Di Monte E. Atypical forms of multiple sclerosis or different phases of a same disease? Neurol Sci. 2004 Nov;25 Suppl 4:S323-5. PubMed PMID: 15727226. 
83. Gorman MP, Healy BC, Polgar-Turcsanyi M, Chitnis T. Increased relapse rate in pediatric-onset compared with adult-onset multiple sclerosis. Arch Neurol. 2009 Jan;66(1):54-9. PubMed PMID: 19139299.

84. Huppke B, Ellenberger D, Rosewich H, Friede T, Gartner J, Huppke P. Clinical presentation of pediatric multiple sclerosis before puberty. European journal of neurology : the official journal of the European Federation of Neurological Societies. 2014 Mar;21(3):441-6. PubMed PMID: 24330201.

85. Fay AJ, Mowry EM, Strober J, Waubant E. Relapse severity and recovery in early pediatric multiple sclerosis. Mult Scler. 2012 Jul;18(7):1008-12. PubMed PMID: 22183939.

86. Koziol LF, Budding D, Andreasen N, D'Arrigo S, Bulgheroni S, Imamizu H, et al. Consensus paper: the cerebellum's role in movement and cognition. Cerebellum. 2014 Feb;13(1):151-77. PubMed PMID: 23996631.

87. Amato MP, Goretti B, Ghezzi A, Lori S, Zipoli V, Moiola L, et al. Cognitive and psychosocial features in childhood and juvenile MS: two-year follow-up. Neurology. 2010 Sep 28;75(13):1134-40. PubMed PMID: 20876467.

88. Till C, Ghassemi R, Aubert-Broche B, Kerbrat A, Collins DL, Narayanan S, et al. MRI correlates of cognitive impairment in childhood-onset multiple sclerosis. Neuropsychology. 2011 May;25(3):319-32. PubMed PMID: 21534686.

89. Waubant E, Chabas D, Okuda DT, Glenn O, Mowry E, Henry RG, et al. Difference in disease burden and activity in pediatric patients on brain magnetic resonance imaging at time of multiple sclerosis onset vs adults. Arch Neurol. 2009 Aug;66(8):967-71. PubMed PMID: 19667217. 
90. Rocca MA, Valsasina P, Absinta M, Moiola L, Ghezzi A, Veggiotti P, et al.

Intranetwork and internetwork functional connectivity abnormalities in pediatric multiple sclerosis. Hum Brain Mapp. 2014 Feb 7. PubMed PMID: 24510680.

91. Wedeen VJ, Wang RP, Schmahmann JD, Benner T, Tseng WY, Dai G, et al.

Diffusion spectrum magnetic resonance imaging (DSI) tractography of crossing fibers. Neuroimage. 2008 Jul 15;41(4):1267-77. PubMed PMID: 18495497.

92. Granziera C, Schmahmann JD, Hadjikhani N, Meyer H, Meuli R, Wedeen V, et al. Diffusion spectrum imaging shows the structural basis of functional cerebellar circuits in the human cerebellum in vivo. PloS one. 2009;4(4):e5101. PubMed PMID: 19340289. Pubmed Central PMCID: 2659746. 


\section{Figure 1:}
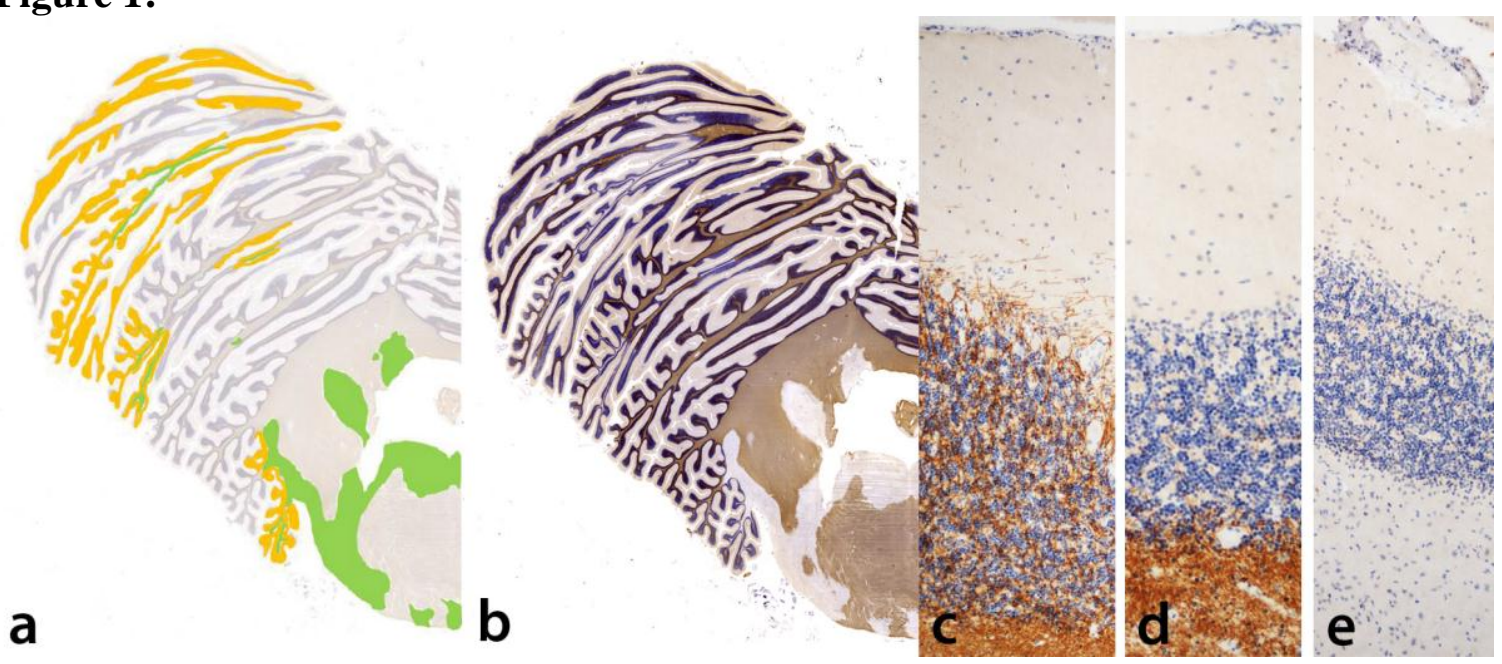

a, b: Low magnification images of the cerebellum, showing white matter (green) and cortical (orange) demyelination. a: schematic drawing of the slide illustrating the demyelination; b: original section, stained by immunohistochemistry for proteolipid protein.

c: Normal myelination pattern of the cerebellar cortex with radial myelinated fibers in the granular layers and tangential myelinated fibers above and below the Purkinje cell layer. $\mathrm{d}$ : Cortical demyelination in MS with loss of myelinated fibers in the Pukinje cell layer and granular layer.

e: Cortico-subcortical demyelinated lesion in the cerebellum, showing myelin loss in the entire cortex and in the subcortical white matter.

\section{Figure 2:}




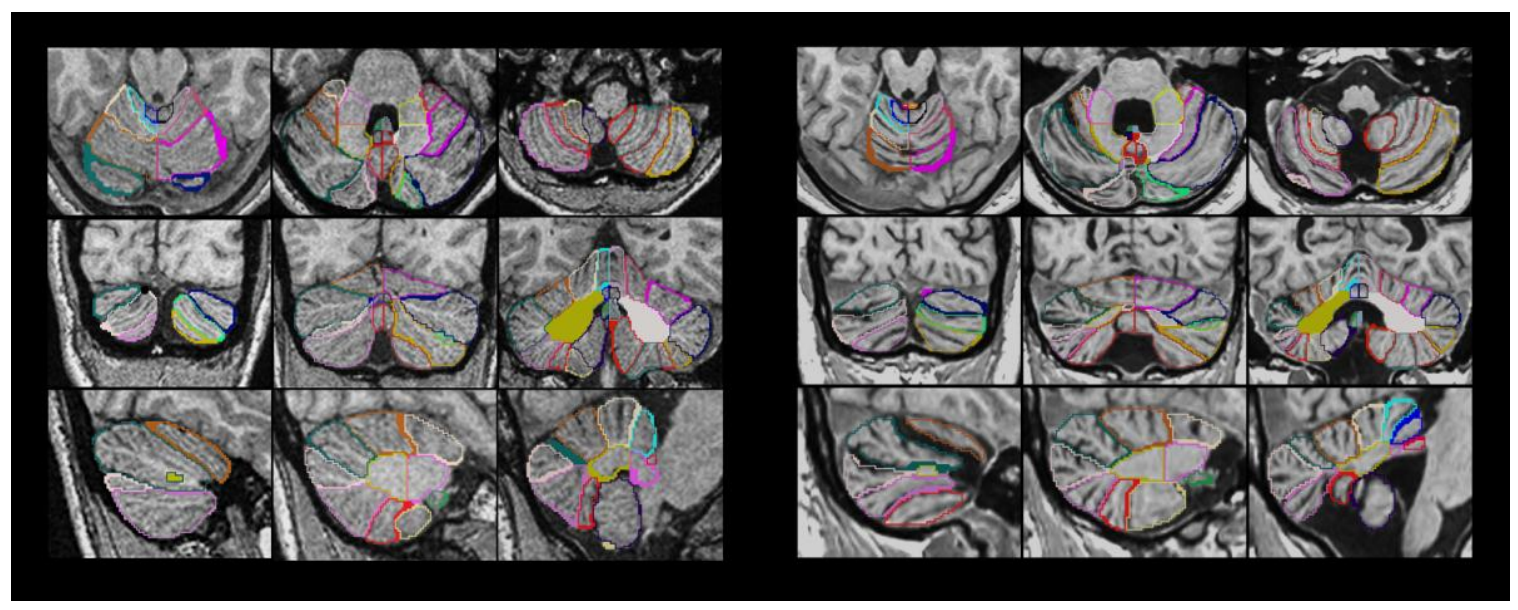

Automatic segmentation of the cerebellar lobules using the RASCAL algorithm (56). The cerebellum of a healthy $30 \mathrm{y}$ old male (left side; manual segmentation from the template library) is displayed in comparison to a $42 \mathrm{y}$ old male with longstanding relapsing-

remitting MS (right side; automatically segmented using RASCAL). The segmentation of the individual lobules is demonstrated in axial (top row), coronal (middle) and sagittal (bottom) plane.

\section{Figure 3:}

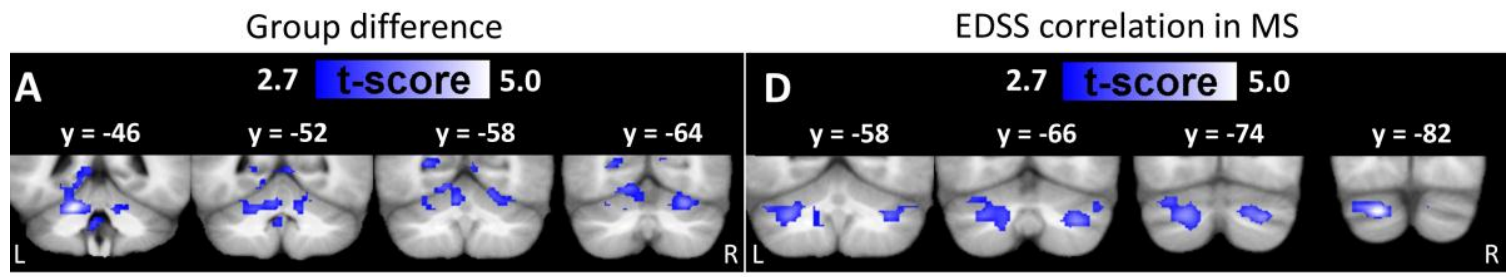
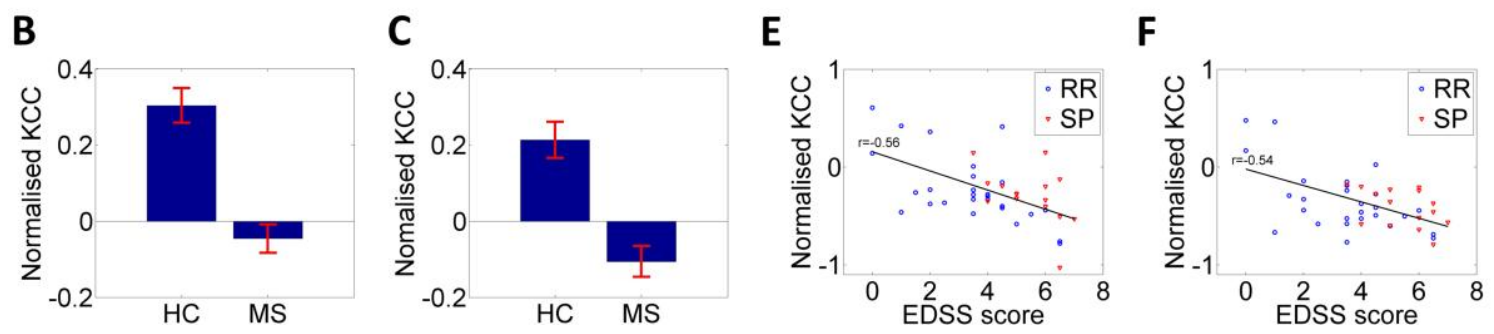

Decrease in local functional connectivity of cerebellar regions in MS (left). 
Coronal t-maps representing voxels with reduced local functional connectivity in MS compared with controls (A). Reduced connectivity was detected in lobules V and VI of the left cerebellum in MS. Left (B) and right (C) cerebellar cluster mean normalized KCC (= Kendall's Coefficient of Concordance) and standard error bars of healthy controls $(=\mathrm{HC})$ and MS patients.

Local functional connectivity of cerebellar regions correlates with disability in MS (right).

Coronal t-maps representing voxels where local functional connectivity correlated with EDSS scores in MS (D). Reduced connectivity was detected in the left Crus I and dentate nucleus. Left (E) and right (F) cerebellar cluster mean normalized KCC for each subject (y-axis) plotted against EDSS scores (x-axis) with a regression line. $\mathrm{KCC}=$ Kendall's Coefficient of Concordance; EDSS = Expanded Disability Status Scale; RR = relapsingremitting multiple sclerosis; $\mathrm{SP}=$ secondary progressive multiple sclerosis. 